\title{
Intradialytic Blood Pressure Abnormalities: The Highs, The Lows and All That Lies Between
}

\author{
Magdalene M. Assimon ${ }^{a, b}$ Jennifer E. Flythe ${ }^{a, c}$ \\ a University of North Carolina Kidney Center, Division of Nephrology and Hypertension, Department of Medicine, \\ UNC School of Medicine, ${ }^{b}$ Department of Epidemiology, UNC Gillings School of Global Public Health, and ${ }^{\mathrm{C} C e c i l ~ G . ~}$ \\ Sheps Center for Health Services Research, University of North Carolina, Chapel Hill, N.C., USA
}

\section{Key Words}

Blood pressure · Hemodialysis · Intradialytic hypotension . Intradialytic hypertension - Blood pressure variability

\begin{abstract}
Background: Frequent blood pressure (BP) measurements are necessary to ensure patient safety during hemodialysis treatments. Intradialytic BPs are not optimal tools for hypertension diagnosis and cardiovascular risk stratification, but they do have critical clinical and prognostic significance. We present evidence associating intradialytic BP phenomena including fall, rise and variability with adverse clinical outcomes and review related pathophysiologic mechanisms and potential management strategies. Summary: Observational studies demonstrate associations between intradialytic hypotension, hypertension and BP variability and mortality. Lack of consensus regarding diagnostic criteria has hampered data synthesis, and prospective studies investigating optimal management strategies for BP phenomena are lacking. Mechanistic data suggest that cardiac, gut, kidney and brain ischemia may lie on the causal pathway between intradialytic hypotension and mortality, and endothelial cell dysfunction, among other factors, may be an important mediator of intradialytic hypertension and adverse
\end{abstract}

outcomes. These plausible pathophysiologic links present potential therapeutic targets for future inquiry. The phenomenon of intradialytic BP variability has not been adequately studied, and practical clinical measures and treatment strategies are lacking. Key Messages: Intradialytic BP phenomena have important prognostic bearing. Clinical practice guidelines for both intradialytic hypotension and hypertension exist, but their underlying evidence is weak overall. Further research is needed to develop consensus diagnostic criteria for intradialytic hypotension, hypertension and $\mathrm{BP}$ variability and to elucidate optimal treatment and prevention strategies for each BP manifestation.

(c) 2015 S. Karger AG, Basel

\section{Introduction}

Blood pressure (BP) measurement is a fundamental part of hemodialysis (HD) administration with measurements taken before and after HD and at frequent intervals during the treatment. It is well recognized that these peridialytic and intradialytic BP measurements are poorly reflective of interdialytic BP behavior and overall cardiovascular disease burden [1-3]. However, such BP measurements are essential for monitoring patient safety during

\section{KARGER 125}

(c) 2015 S. Karger AG, Base

0250-8095/15/0425-0337\$39.50/0
Jennifer E. Flythe, MD, MPH

University of North Carolina Kidney Center

7024 Burnett-Womack CB \#7155

Chapel Hill, NC 27599-7155 (USA)

www.karger.com/ajn 
dialysis. Peridialytic BPs and adverse clinical outcomes have a well-described ' $U$ '-shaped association $[4,5]$, but no prospective studies have established optimal intervention thresholds on either end of the BP spectrum. Overt intradialytic BP abnormalities such as hypotension in a pale, diaphoretic patient or hypertension in a patient with headache and vision change are impossible to ignore. Such drastic presentations spark immediate intervention, and elegant studies demonstrating harm are not needed. While these extreme BP events occur more often than desired, they are relatively infrequent in today's era of bicarbonatebased dialysate and volumetric ultrafiltration (UF).

Instead, the clinical dilemmas and prognostic uncertainties lie along a spectrum of seemingly minor and often asymptomatic intradialytic BP falls, elevations and fluctuations. Such uncertainties stem from lack of consensus definitions for intradialytic hypotension, hypertension and $\mathrm{BP}$ variability and the paucity of evidence on effective intervention and prevention strategies. These evidence limitations combined with absence of associated symptoms contribute to the tendency to conflate asymptomatic BP fluctuations with 'normal' BP. However, growing evidence suggests harm from aberrant, asymptomatic intradialytic BP changes. Currently, a hierarchy exists with regards to the volume and quality of existing literature. Intradialytic hypotension has both the largest and strongest clinical evidence base, followed by intradialytic hypertension and intradialytic BP variability, respectively. Herein, we review evidence associating different intradialytic BP phenomena, including BP fall, rise and variability, with adverse clinical outcomes, summarize their pathophysiology and management, and identify uncertainties requiring further research.

\section{Dialysis Unit BP Measurements}

Clinicians have a plethora of BP measurements available when caring for in-center, thrice-weekly, maintenance HD patients. The most abundant measurements are peridialytic BPs, measurements taken before and after $\mathrm{HD}$, and intradialytic BPs, measurements assessed at frequent intervals during HD. Despite their accessibility, peridialytic and intradialytic BPs are limited in their diagnostic capacity. Ambulatory and home BP measurements are more reliable for diagnosing hypertension and performing cardiovascular risk stratification than peridialytic BPs $[2,6,7]$. Technical, patient and HD procedural factors thwart in-center BP diagnostic accuracy. In a study comparing BP measurement techniques,
Rahman et al. [8] demonstrated BP overestimation with HD machine-automated measurements compared to BPs taken by a sphygmomanometer operated in accordance with American Heart Association guidelines. Numerous potential sources for error in machine-measured BPs exist. First, equipment error introduced by incorrectly sized cuffs or out-of-date BP machine validation and calibration may contribute to inaccuracies [9]. Second, patient position and recent activities including caffeine ingestion, exercise and smoking may impact measurements. Third, factors related to the dialysis vascular access and underlying vascular disease are also salient. While BP is typically taken in the arm opposite to the access, lower extremity BPs are measured when brachial measurements are not possible. Peripheral amplification of pulse pressure and poorly sized cuffs lead to higher BP readings in the lower extremities [9]. These potential measurement errors complicate not only chairside, clinical BP interpretation, but also create potential inaccuracies in research utilizing routinely measured dialysis unit BPs.

Even in studies where BP measurement technique is standardized and patient differences are accounted for, in-center BP readings do not correlate well with ambulatory BPs [10]. Factors unique to the dialytic period including fluid and osmolar shifts and erythropoietin stimulating agents (ESAs) affect cardiac output and BP. These dynamic conditions combined with high potential for measurement error limit the diagnostic capacity of incenter BPs. Despite these limitations, in-center BP measurements do have substantial clinical and prognostic importance, particularly with regard to identifying dynamic $\mathrm{BP}$ changes as we review in the following sections.

\section{Intradialytic BP Patterns}

Observational studies of intradialytic BP patterns have identified extremes of BP fall, rise and fluctuations as important prognostic indicators. Pre- to post-dialysis BP change has been demonstrated to have a J- or U-shaped mortality association in epidemiologic studies $[4,5]$. In a recent analysis of over 110,000 patients, Park et al. [5] reported a U-shaped association between mean pre- to post-HD systolic BP change and mortality. Authors found that peak survival was observed in patients with $\mathrm{BP}$ fall of $14 \mathrm{~mm} \mathrm{Hg}$ during HD. Patients with intradialytic BP falls $>30 \mathrm{~mm} \mathrm{Hg}$ or BP rise $>0 \mathrm{~mm} \mathrm{Hg}$ had greater mortality. In analyses stratified by pre-HD systolic BP, Ushaped associations between BP change and outcomes were found only in pre-HD systolic BP categories 
Fig. 1. Patterns of intradialytic BP behav-

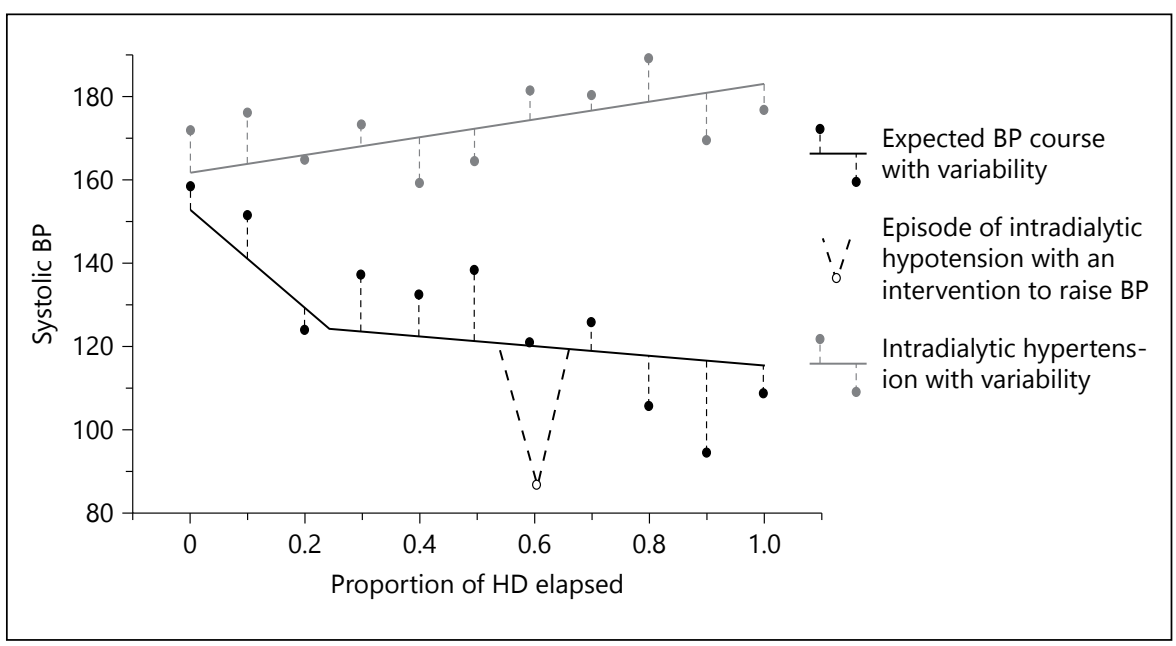
ior.

\section{Intradialytic BP Fall}

tant limitation as a prognostic metric, because it does not reflect individual intradialytic BP measurements such as nadir systolic BP. The measure thus falls short in accurately capturing intradialytic BP fluctuations of known clinical importance. Such intradialytic BP fluctuations are common. BP behavior during $\mathrm{HD}$ is influenced by a variety of physiologic and procedural factors including UF-driven fluid shifts, serum osmolality changes, neurohormonal axis and inflammatory pathway activation and dialytic removal of antihypertensives and other vasoactive substances. High burdens of comorbid disease and non-traditional cardiovascular risk factors such as stiff vasculature, impaired vasoreactivity and autonomic dysfunction render dialysis patients particularly vulnerable to hemodynamic compromise from BP fluctuations.

In a study of intradialytic BPs in 218 patients across $>2,000 \mathrm{HD}$ treatments, Dinesh et al. [11] characterized the intradialytic temporal trend of systolic BP behavior with a 2-slope linear spline. The model describes the following: (1) systolic BP at HD start, (2) a rapid decrease in systolic BP during the first $25 \%$ of treatment (slope of $-25.5 \pm 1.5 \mathrm{~mm} \mathrm{Hg}$ ) and then (3) a more gradual decline in systolic BP in the latter $75 \%$ of treatment (slope of $-5.8 \pm 0.5 \mathrm{~mm} \mathrm{Hg}$ ). Higher UF volume and rate and calcium acetate use were associated with greater pre-HD BP and a more rapid decline in both early- and late-HD BP slopes. Departures from this expected BP course include precipitous $\mathrm{BP}$ drops (intradialytic hypotension), pre- to post-dialysis BP elevation (intradialytic hypertension) and more subtle BP fluctuations (intradialytic BP variability) as shown in figure 1 . All $3 \mathrm{BP}$ phenomena are associated with adverse clinical outcomes.

BP Abnormalities during HD

\section{Epidemiology and Definitions}

Intradialytic hypotension is a well-recognized HD complication, occurring in $10-70 \%$ of treatments, depending on the definition [12]. Patient and clinical characteristics associated with intradialytic hypotension include older age, female sex, longer dialysis vintage, diabetes, lower pre-dialysis BP, lower albumin and higher body mass index $[12,13]$. Low $\mathrm{BP}$ during $\mathrm{HD}$ has been associated with a range of clinical and pathogenic consequences including inadequate dialysis dose, myocardial stunning, brain atrophy, vascular access thrombosis and increased mortality [12, 14-17]. Surprisingly, we lack the diagnostic criteria for intradialytic hypotension and consensus on optimal intervention thresholds.

Most clinical practice guidelines require the presence of symptoms or administration of interventions to fulfill intradialytic hypotension diagnostic criteria, but many epidemiologic studies associating hypotension with adverse outcomes are based on BP values alone. The $\mathrm{Na}$ tional Kidney Foundation's Kidney Disease Outcomes Quality Initiative (KDOQI) and European Best Practices Guidelines define intradialytic hypotension as a decrease in systolic BP $\geq 20 \mathrm{~mm} \mathrm{Hg}$ or a drop in mean arterial pressure (MAP) $\geq 10 \mathrm{~mm} \mathrm{Hg}$ during $\mathrm{HD}$ with associated symptoms $[18,19]$. In the Hemodialysis Study (HEMO Study), intradialytic hypotension was defined as hypotension requiring either saline infusion or UF rate or blood flow reduction. Administrative research databases typically lack symptom and complete intervention data, necessitating definitions utilizing BP values alone. Such definitions are based on requisite BP falls (10-40 $\mathrm{mm} \mathrm{Hg}$ ) or 
nadir intradialytic BP thresholds $(60-100 \mathrm{~mm} \mathrm{Hg})$ [2023]. Other definition formulations combine requisite drops or thresholds with the presence of symptoms and/ or interventions. For example, Chesterton et al. [24] defined intradialytic hypotension with a nadir systolic BP $<100 \mathrm{~mm} \mathrm{Hg}$ or a $>10 \%$ intradialytic BP fall plus the presence of symptoms. Unfortunately, definition discrepancies have limited data synthesis and hindered the development of evidence-based management guidelines.

Recently, Flythe et al. [12] aimed to address the lack of uniform intradialytic hypotension diagnostic criteria by examining associations between commonly used definitions and mortality. This study clearly illustrates the influence of hypotension definition on prevalence estimates. Intradialytic hypotension defined as systolic BP fall $>20 \mathrm{~mm} \mathrm{Hg}$ was observed in $68 \%$ of treatments during the exposure period. In contrast, hypotension defined as systolic BP fall below $90 \mathrm{~mm} \mathrm{Hg}$ was present in only $\sim 10 \%$ of the exposure treatments. When outcomes were considered, nadir systolic BP of $90 \mathrm{~mm} \mathrm{Hg}$ was associated with greater all-cause mortality, adjusted odds ratio (95\% CI), 1.56 (1.05-2.31) in the HEMO Study cohort and 1.30 (1.07-1.57) in the large dialysis organization cohort. Other intradialytic hypotension definitions were not associated with mortality. Neither addition of symptoms nor interventions to nadir-based definitions strengthened their associations with mortality. This finding stands in contrast to the existing clinical guideline intradialytic hypotension definitions that require symptoms or interventions $[18,19]$. In a recent prospective study, Meredith et al. [25] demonstrated poor correlation between symptoms and nursing interventions for hypotension, further underscoring potential inaccuracy associated with symptom-based definitions. Overall, existing data suggest that a nadir-based intradialytic hypotension definition may be optimal for capturing mortality risk.

\section{Pathophysiology}

Maintenance of adequate blood volume during dialysis is dependent on multiple patient and HD factors. In absence of serious medical conditions such as infection, arrhythmias, pericardial tamponade, myocardial infarction and hemorrhage and HD complications such as hemolysis, air embolism and dialyzer reactions, intradialytic hypotension ensues when the pace of fluid removal exceeds the pace of plasma refill and associated physiologic compensatory responses. Decreased effective arterial blood volume during overly aggressive UF leads to decreased cardiac filling, decrements in cardiac output and, ultimately, hypotension. There are numerous patient, cardio- vascular, volume and HD treatment-related risk factors for intradialytic hypotension (fig. 2a). Compensatory mechanisms include increased cardiac output, enhanced plasma refill, passive venoconstriction and increases in arterial tone. Cardiac output is augmented by increased contractility and, to a lesser extent, increased heart rate [26].

The pathophysiologic mechanisms underlying intradialytic hypotension provide insight into potential management strategies. Dialysate sodium, plasma albumin and the magnitude of hydrostatic capillary force all influence plasma refill. Exposure to higher dialysate-serum sodium gradients increases fluid mobilization into the intravascular space. Similarly, higher plasma osmolality, associated with greater albumin levels, enhances refill. Intradialytic osmolality decline from uremic toxin removal and sodium gradient equilibration lead to slowed vascular refill over the treatment course. Procedural factors such as warm dialysate, acetate buffer or eating during dialysis increase the risk of hypotension by decreasing peripheral resistance. Autonomic dysfunction and impaired baroreceptor sensitivity dampen the compensatory cardiac responses to these blood volume reductions [27]. Cardiac abnormalities such as diastolic dysfunction, atrial fibrillation, left ventricular hypertrophy and ischemic heart disease also contribute. When compensatory responses for reduced cardiac filling reach their limits, BP falls [26].

Furthermore, emerging data suggest that episodes of intradialytic hypotension beget future hemodynamic instability. Intradialytic hemodynamic compromise has been linked to episodic stunning of the myocardium [14, 15]. Over time, repeat ischemia induces cardiac hypertrophy and fibrosis, further impairing response to decreased filling pressures and increasing risk for hemodynamic instability. Related, intradialytic gut hypoperfusion may increase systemic endotoxin levels. Endotoxemia is linked to chronic inflammation and cardiovascular risk via potentiation of pro-inflammatory cytokine generation, oxidative stress and endothelial dysfunction [28]. Finally, hypoperfusion injury to the kidney may accelerate the loss of native kidney function among patients with residual kidney function, an independent risk factor for mortality [29].

\section{Outcome Associations}

Table 1 summarizes representative studies of intradialytic hypotension and mortality. While intradialytic hypotension is frequently cited as a mortality risk factor, observational studies have yielded mixed results. A 2003 Hungarian study found no association between intradia- 


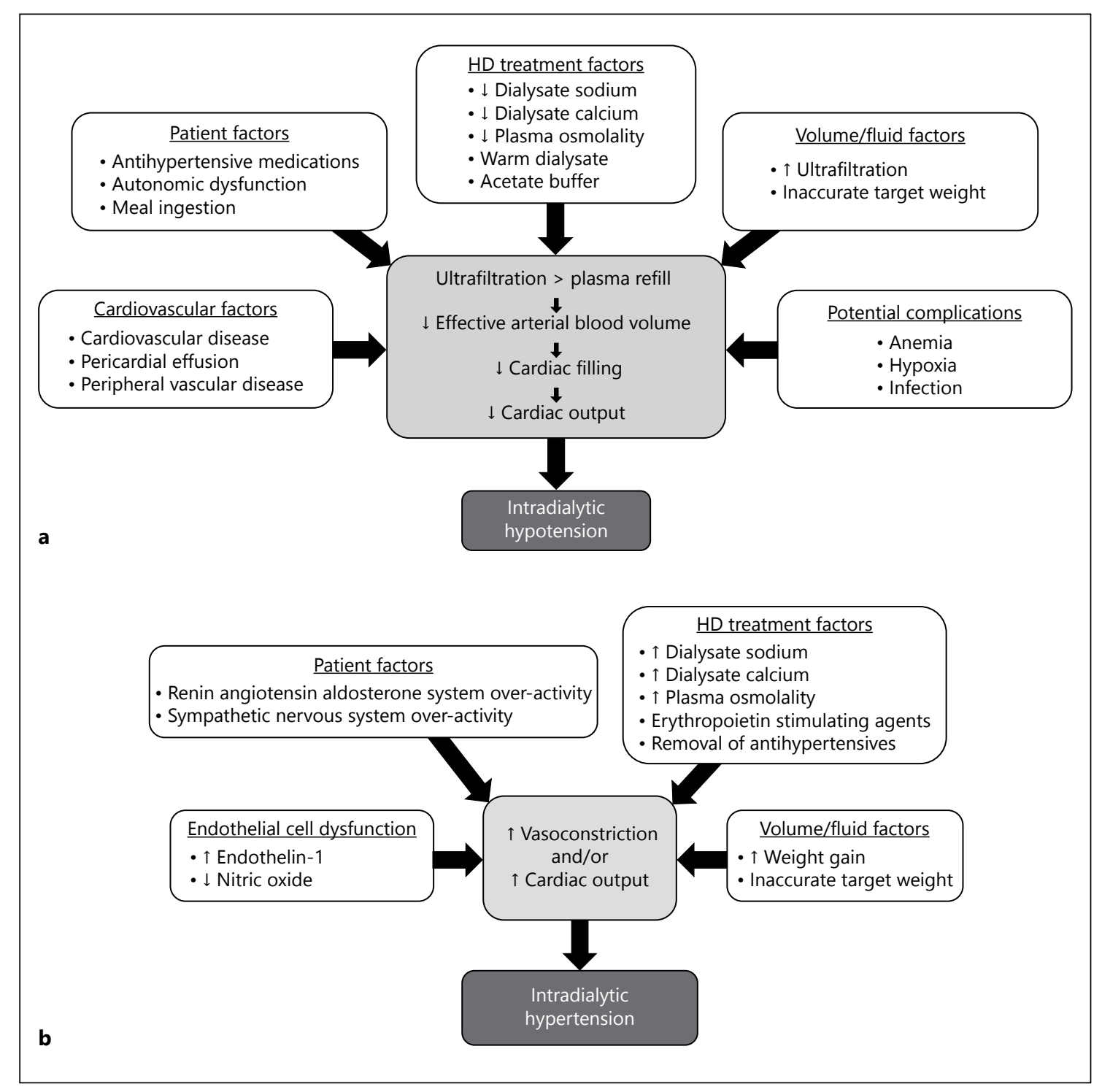

Fig. 2. Pathophysiology of intradialytic hypotension (a) and hypertension (b).

lytic hypotension and mortality [30]. In contrast, a 2004 Japanese analysis demonstrated an association between intradialytic hypotension and greater mortality with lower nadir systolic BP associating with higher all-cause death risk [31]. In 2014, Stefánsson et al. [32] examined the relationship between intradialytic hypotension and all-cause mortality and a composite outcome of myocardial infarction, stroke and cardiovascular mortality in a US cohort, finding associations with both. These discrepant findings may, in part, be explained by differences in hypotension definitions and number of HD treatments used to identify hypotensive episodes. The Japanese study considered only one HD treatment, whereas the Hungar- ian and US analyses classified intradialytic hypotension over longer periods, 10 months and 90 days, respectively. In a 2 cohort observational analysis, Flythe et al. [12] demonstrated an association between intradialytic nadir systolic BP $<90 \mathrm{~mm} \mathrm{Hg}$ and all-cause mortality. These findings were robust in both cohorts and across varying levels of pre-HD systolic BP. Beyond mortality, intradialytic hypotension has been associated with vascular access thrombosis and mesenteric ischemia $[16,22]$.

Studies considering the associations of $\mathrm{BP}$ fall and intermediate outcomes link hemodynamic insults to a range of adverse end-organ sequelae including cardiac ischemia, gut ischemia and structural brain changes. In 2 
Table 1. Studies of intradialytic hypotension and mortality associations among HD patients

\begin{tabular}{|c|c|c|c|c|}
\hline Reference, year & n (country) & Exposure(s) & Outcome(s) & Major findings \\
\hline $\begin{array}{l}\text { Tislér et al. } \\
\text { [30], } 2003\end{array}$ & $\begin{array}{l}263 \\
\text { (Hungary) }\end{array}$ & $\begin{array}{l}\text { Nadir systolic BP } \leq 90 \mathrm{~mm} \mathrm{Hg} \text { or systolic } \\
\text { BP fall } \geq 30 \mathrm{~mm} \mathrm{Hg} \text { plus the presence of } \\
\text { associated symptoms and an intervention } \\
\text { present in } \geq 10 \mathrm{HD} \text { treatments in a } \\
10 \text {-month period }\end{array}$ & All-cause mortality & $\begin{array}{l}\text { - Frequent intradialytic hypotension was not } \\
\text { associated with all-cause mortality }\end{array}$ \\
\hline $\begin{array}{l}\text { Shoji et al. } \\
{[31], 2004}\end{array}$ & $\begin{array}{l}1,206 \\
\text { (Japan) }\end{array}$ & $\begin{array}{l}\text { Intradialytic systolic BP fall } \geq 40 \mathrm{~mm} \mathrm{Hg} \\
\text { in a single baseline } \mathrm{HD} \text { session }\end{array}$ & 2-year all-cause mortality & $\begin{array}{l}\text { - Intradialytic hypotension was associated with } \\
\uparrow \text { mortality across all pre-HD BP strata } \\
\text { - } \downarrow \text { Nadir systolic BP was associated with } \uparrow \\
\text { mortality }\end{array}$ \\
\hline $\begin{array}{l}\text { Stefánsson } \\
\text { et al. [32], } 2014\end{array}$ & $\begin{array}{l}39,497 \\
\text { (US) }\end{array}$ & $\begin{array}{l}\text { Intradialytic systolic BP fall } \geq 20 \mathrm{~mm} \mathrm{Hg} \\
\text { and } \geq 2 \text { of the following: UF rate reduction, } \\
\text { blood flow reduction, saline administration } \\
\text { or premature cessation of HD present in } \\
\geq 1 \mathrm{HD} \text { treatment in a } 90 \text {-day period }\end{array}$ & $\begin{array}{l}\text { - All-cause mortality } \\
\text { - Cardiovascular composite } \\
\text { event (myocardial } \\
\text { infarction, stroke, } \\
\text { cardiovascular mortality) }\end{array}$ & $\begin{array}{l}\text { - Intradialytic hypotension was associated with } \\
\uparrow \text { mortality } \\
\text { - Intradialytic hypotension was associated with } \\
\text { an } \uparrow \text { in cardiovascular composite event }\end{array}$ \\
\hline $\begin{array}{l}\text { Flythe et al. } \\
{[12], 2015}\end{array}$ & $\begin{array}{l}10,392 \\
\text { (US) }\end{array}$ & $\begin{array}{l}\text { - HEMO Study cohort: intradialytic nadir } \\
\text { systolic } \mathrm{BP}<90 \mathrm{~mm} \mathrm{Hg} \text { present in } \geq 30 \% \\
\text { of } \mathrm{HD} \text { treatments in the pre-randomization } \\
\text { period plus } 4 \text { months }(7-11 \text { treatments) } \\
\text { - Large dialysis organization cohort: } \\
\text { intradialytic nadir systolic } \mathrm{BP}<90 \mathrm{~mm} \mathrm{Hg} \\
\text { present in } \geq 30 \% \text { of } \mathrm{HD} \text { treatments in a } \\
\text { 30-day period ( } 12-15 \text { treatments) } \\
\text { - Other intradialytic hypotension definitions: } \\
\text { intradialytic systolic BP fall } \geq 20 \text { mm Hg } \\
\text { and } \geq 30 \text { mm Hg (separately); nadir } \\
\text { intradialytic systolic BP }<100 \text { mm Hg; } \\
\text { combinations of fall and nadir definitions; } \\
\text { definitions with symptom or intervention } \\
\text { requirements }\end{array}$ & All-cause mortality & $\begin{array}{l}\text { - Intradialytic hypotension was associated with } \\
\uparrow \text { mortality in both study cohorts } \\
\text { - } \uparrow \text { Frequency of intradialytic hypotension was } \\
\text { associated with an incremental } \uparrow \text { in mortality } \\
\text { - Other definitions were not associated with } \\
\text { mortality } \\
\text { - Addition of symptoms or interventions to a } \\
\text { nadir systolic BP < } 90 \text { mm Hg definition did } \\
\text { not augment the mortality association }\end{array}$ \\
\hline
\end{tabular}

studies Burton et al. [15,33] describe greater intradialytic BP fall among patients with cardiac ischemia as evidenced by myocardial wall stunning on echocardiography. However, simultaneous assessments of BP and echocardiography limit causality inferences. Troponin elevations over the course of dialysis further supports HD treatment-associated cardiac ischemia [34]. Furthermore, hypotension has been linked to gut ischemia. Interruptions to bowel perfusion can result in endotoxin translocation to the bloodstream. A study by McIntyre et al. [28] reported elevated blood endotoxin levels among HD patients with greater intradialytic BP fall. Additionally, hypoperfusioninduced brain injury among HD patients may also contribute to adverse outcomes [17]. Firm conclusions about the associations of and causal pathways between intradialytic hypotension and these intermediate outcomes are limited by the use of cross-sectional study designs, small sample sizes and potential residual confounding from factors such as low pre-HD BP, diabetes, comorbid cardiac disease and hypoalbuminemia not accounted for in these descriptive studies. Despite their limitations, these mechanistic investigations provide compelling evidence supporting associations of intradialytic hemodynamic instability and intermediate, non-fatal outcomes including hypoperfusion-induced heart, gut and brain insults.

\section{Management}

Frank symptomatic intradialytic hypotension mandates swift nursing intervention. Acute management may include stopping UF or HD entirely, placing the patient in the Trendelenburg position and/or administering intravenous fluid and supplemental oxygen. Intervention selection is typically driven by event severity and is left to clinical judgment. Evidence supporting BP thresholds for intervention and optimal approaches for BP restoration are limited. For intravascular volume repletion, most clinicians rely on isotonic saline but options include hypertonic saline, hypertonic glucose, $5 \%$ dextrose and albumin. Use of albumin is expensive, and a small randomized trial suggested equivalence between saline and 
albumin [35]. Hypertonic glucose may be the most effective at restoring blood volume, but use is limited by the high diabetes prevalence among HD patients [36]. Once hemodynamic stability is restored, attention turns to ruling out causative procedural complications such as hemolysis, air embolus and dialyzer reactions. Non-procedural causes such as pericardial tamponade, cardiac ischemia, hemorrhage and infection should be assessed via history and examination. In cases where BP is not responsive to interventions or when hypotension is accompanied by chest or abdominal pain, dyspnea or fever, patients may require hospital evaluation for cardiac ischemia, sepsis and occult bleeding.

While restoration of the circulatory volume is the priority during episodes of intradialytic hypotension, downstream consequences of interventions such as fluid administration, target weight adjustment and dialysate sodium adjustment should not be discounted. First, patients with frequent hypotension are at risk for recurrent target weight misses and chronic volume overload. Both of these clinical scenarios are associated with mortality $[37,38]$. Clinical experience reveals that target weights are often adjusted upward to 'match' achieved post-weights following hypotension. In these cases, clinicians assume the target weight is underestimated. While target weight adjustment is occasionally required, it is the authors' opinion that weight change should not be the default response to hypotensive episodes [39]. Hypotensive events often reflect a mismatch in UF and refill rates rather than total body volume depletion. Unfortunately, we lack objective measures to help distinguish these situations. Clinical clues such as the intradialytic timing of the hypotensive event and tools such as blood volume monitors may be helpful [40]. Hypotension early in HD may reflect preexisting hypovolemia and should prompt reassessment of target weight, while late treatment hypotension may represent either an excessive UF rate or target weight overestimation. Other precipitants also remain plausible. Second, hypertonic saline administration (and to a lesser extent, isotonic saline) and use of wide dialysate-serum sodium gradients lead to sodium loading, a risk factor for interdialytic thirst and subsequent interdialytic weight gain (IDWG) [41, 42]. Greater IDWG is associated with more frequent intradialytic hypotension and greater cardiovascular morbidity and mortality [43]. Related, sodium modeling, an effective hypotension preventive maneuver, has been rendered obsolete due to associated sodium loading [41]. Ultimately, clinicians must balance the risk of future hypotensive events against the risk of volume overload.

BP Abnormalities during HD
Table 2. Clinical guidelines for intradialytic hypotension prevention [19]

First-line

Dietary counseling (sodium restriction)

Avoidance of food ingestion during dialysis

Clinical reassessment of target weight

Use of bicarbonate dialysis buffer

Use of dialysate temperature of $36.5^{\circ} \mathrm{C}$

Review of dosing and timing of antihypertensives

Second-line

Objective measures for reassessment of target weight

Cardiac evaluation

Gradual reduction of dialysate temperature (lowest $35^{\circ} \mathrm{C}$ )

Individualized blood volume controlled feedback

Increased dialysis treatment time or extra treatment

\section{Third-line}

Midodrine

L-Carnitine supplementation

Dialysis modality change

Acute hypotensive episodes should be contextualized in the patient's recent clinical history. Data demonstrate a dose-response association between intradialytic hypotension and mortality; more frequent hypotension is associated with an incrementally greater risk of death [12]. Preventive strategies should be considered in patients with recurrent hypotension. The European Best Practice Guidelines for intradialytic hypotension prevention are presented in table 2 [19]. Preventative strategies should be accompanied by a medication review with focus on dosing and timing of antihypertensives, opiates and other sedating medications. Evaluation for underlying ischemic heart disease and heart failure may be indicated.

Definitive, evidence-based intradialytic hypotension prevention strategies are few. Dialysate cooling has the best efficacy data with randomized trial data showing decreased brain white matter changes with cooled dialysate and a systematic review of 22 studies finding clinical benefit to cooled dialysate $[44,45]$. However, formal assessments of patient tolerance and preference are lacking. Dialysis treatment time extension or additional HD treatments to facilitate more gradual fluid removal are helpful for some patients, but implementation of these strategies are limited by patient acceptance [46]. Additional HD treatment-related hypotensive preventive strategies include the following: UF modeling, the practice of varying the UF rate during $\mathrm{HD}$, and sequential dialysis, the practice of isolated UF followed by UF plus HD. Both prac- 
tices are intended to match UF to plasma refill rates by maximizing UF at times of greatest hydration and oncotic pressure, but neither practice has been well studied. Finally, dialysate composition changes can be considered. Increased dialysate calcium may improve hemodynamic stability through augmented cardiac contractility, but concerns about calcium balance limit widespread use [47].

In patients with recurrent hypotension despite preventative measures, addition of midodrine, a selective alpha-1 adrenergic agonist, may be considered. A systematic review of 10 studies and 117 patients found that compared with control, midodrine was associated with increased nadir and post-HD systolic BPs [48]. Midodrine is typically dosed 15-30 minutes before dialysis but dosing may be split into pre-HD and mid-HD doses to help mitigate late treatment hypotension. Vigilance for side effects including urinary retention, supine hypotension and pruritus is warranted [48]. The supplement, Lcarnitine, has not proven effective in preventing intradialytic hypotension [49]. Less well-studied preventative medications include sertraline and vasopressin $[50,51]$. Among patients with refractory, recurrent hypotensive episodes, change to peritoneal, nocturnal or daily dialysis may be warranted.

\section{Intradialytic BP Rise}

\section{Epidemiology and Definitions}

While less common than intradialytic hypotension, intradialytic hypertension is another BP phenomenon with important prognostic significance. Patient and clinical characteristics associated with intradialytic BP rise include older age, lower body weight, lower serum creatinine and albumin and utilization of more antihypertensive medications $[52,53]$. The prevalence of intradialytic hypertension is in the range of $5-15 \%$ among maintenance HD patients, depending on the definition $[54,55]$. Currently, there is no universally accepted definition of intradialytic hypertension. It is typically defined as BP increase during or immediately after $\mathrm{HD}$, resulting in post-HD BP $>130 / 80 \mathrm{~mm} \mathrm{Hg}$, the KDOQI hypertension threshold [54]. Clinical investigations of this BP abnormality have used a range of definitions with varied thresholds of systolic BP or MAP increase ( $\geq 10$ or $15 \mathrm{~mm} \mathrm{Hg}$ ) [52]. Others have selected more general definitions such as hypertension late in dialysis after the occurrence of the majority of UF or BP rise resistant to UF [56]. Some definitions are limited to sub- populations such as patients with de novo hypertension with ESA initiation, thereby narrowing generalizability [57].

\section{Pathophysiology}

The pathophysiology underlying paradoxical intradialytic BP rise is not fully understood, but data suggest interplay among positive sodium balance, volume overload, activation of the renin-angiotensin-aldosterone system (RAAS) and sympathetic nervous system, hemodialytic removal of antihypertensives, endothelial cell dysfunction, ESAs and bone mineral disease axis abnormalities (fig. 2b). Hypervolemia is a well-recognized risk factor for hypertension among HD patients and is the cause of intradialytic hypertension in a subset of patients $[58,59]$. In one study, additional UF reduced cardiac dilation on echocardiography and lowered cardiac index and MAP [58]. However, factors beyond volume overload are important mediators of intradialytic hypertension in many patients.

Sympathetic nervous system overactivity, RAAS activation and associated vasoconstriction are plausible contributors. However, patients with intradialytic hypertension experience an intradialytic rise in systemic vascular resistance without a consistent, concurrent increase in catecholamine or renin levels, signifying that other mechanisms may drive the development of intradialytic hypertension [60]. In addition, other contributors to intradialytic hypertension include dialytic removal of antihypertensive medications (e.g., atenolol, metoprolol and angiotensin converting enzyme (ACE) inhibitors) and a positive calcium balance conferred from higher dialysate calcium concentrations [54].

Recent investigations have established endothelial cell dysfunction as a key mediator in intradialytic hypertension. Endothelial cells contribute to BP homeostasis by synthesizing and releasing humoral factors such as nitric oxide, a smooth muscle vasodilator and endothelin-1, a vasoconstrictor. Among patients with intradialytic hypertension, studies have demonstrated that endothelin-1 levels rise during dialysis while systemic nitric oxide levels remain inappropriately low $[60,61]$. ESA may contribute to intradialytic hypertension via this mechanism [62]. The role of impaired endothelial cell response to HD is further supported by studies demonstrating a decrease in intradialytic hypertension frequency in response to the beta blocker carvedilol, a medication that suppresses endothelin-1 release in vitro [63]. Additionally, greater dialysate sodium may contribute to intradialytic hypertension through 2 mechanisms: enhanced 
Table 3. Studies of intradialytic hypertension and mortality associations among HD patients

\begin{tabular}{|c|c|c|c|c|}
\hline $\begin{array}{l}\text { Reference, } \\
\text { year }\end{array}$ & $\begin{array}{l}\text { Study, n } \\
\text { (country) }\end{array}$ & Exposure(s) & Main outcome(s) & Major findings \\
\hline $\begin{array}{l}\text { Inrig et al. } \\
{[52], 2007}\end{array}$ & $\begin{array}{l}443 \\
\text { (US; } \\
\text { Canada) }\end{array}$ & $\begin{array}{l}\text { - Intradialytic hypertension was not explicitly defined, } \\
\text { but a mean rise in pre- to post-systolic BP } \geq 10 \mathrm{~mm} \mathrm{Hg} \\
\text { was assessed } \\
\text { - Mean systolic BP values were computed from } \\
\text { readings in } 4 \mathrm{HD} \text { treatments occurring in the } \\
\text { pre-intervention period and the } 1 \text { st week of the study }\end{array}$ & $\begin{array}{l}\text { Composite event: } \\
\text { all-cause mortality } \\
\text { and non-vascular } \\
\text { access-related } \\
\text { hospitalization at } \\
6 \text { months }\end{array}$ & $\begin{array}{l}\text { - Rise in pre- to post-HD } \\
\text { systolic BP was associated } \\
\text { with } \uparrow \text { odds of the composite } \\
\text { outcome }\end{array}$ \\
\hline $\begin{array}{l}\text { Inrig et al. } \\
{[53], 2009}\end{array}$ & $\begin{array}{l}1,748 \\
\text { (US) }\end{array}$ & $\begin{array}{l}\text { - Intradialytic hypertension was not explicitly } \\
\text { defined, but changes in systolic BP during HD } \\
\text { measured as differences in post- and pre-HD } \\
\text { systolic BP were assessed } \\
\text { - Mean systolic BP values were computed from } \\
3 \text { consecutive HD treatments occurring prior to } \\
\text { study enrollment }\end{array}$ & $\begin{array}{l}\text { 2-year all-cause } \\
\text { mortality }\end{array}$ & $\begin{array}{l}\text { - Every } 10 \mathrm{~mm} \mathrm{Hg} \text { rise in } \\
\text { pre- to post-HD systolic BP } \\
\text { was associated with a } 12 \% \uparrow \\
\text { in mortality risk }\end{array}$ \\
\hline
\end{tabular}

IDWG and stimulated release of endothelial-derived vasoregulators. A small crossover trial demonstrated lower mean BPs with use of lower dialysate sodium but no change in intradialytic endothelin-1 or nitric oxide levels. Authors postulated that carryover effects from the study arms may have inhibited detection of changes in vasoregulators [64].

\section{Outcome Associations}

Paradoxical intradialytic BP rise has been noted for decades, but its association with cardiovascular morbidity and mortality has only recently been recognized. Table 3 provides an overview of studies investigating intradialytic hypertension and mortality associations. In a post-hoc analysis of the Crit-line Intradialytic Monitoring Benefit Study (CLIMB Study), Inrig et al. [52] found that patients whose $\mathrm{BP}$ rose or failed to lower with $\mathrm{HD}$ had a twice the odds of non-vascular access-related hospitalization or death at 6 months compared to patients with pre- to postHD BP fall. In an incident HD cohort, Inrig et al. [53] found that every $10 \mathrm{~mm} \mathrm{Hg}$ increase in systolic BP during HD was independently associated with increased mortality, hazard ratio $(95 \% \mathrm{CI})$ of $1.12(1.05-1.21)$. The risk associated with intradialytic hypertension was magnified in patients with low pre-HD systolic $\mathrm{BP}(<120 \mathrm{~mm} \mathrm{Hg})$, raising the possibility of residual confounding from ambient health status. The associations of intradialytic hy- pertension and adverse outcomes are also supported by results from a prospective Taiwanese study showing an association between pre- to post-HD BP rise $>5 \mathrm{~mm} \mathrm{Hg}$ and mortality [65]. Finally, in a non-outcome-based study, Van Buren et al. [66] demonstrated that HD patients with intradialytic hypertension have higher interdialytic BPs, providing evidence of an enhanced cumulative hypertensive burden that may contribute to accelerated left ventricular hypertrophy and associated adverse cardiovascular events.

\section{Management}

The proposed pathophysiology underlying intradialytic hypertension is multifactorial and, as such, presents several targets for intervention. Potential interventions include those aimed at mitigating volume overload, sympathetic over-activity, RAAS activation and endothelial cell dysfunction. Other strategies include antihypertensive medication and dialysate composition changes. As chronic volume overload is linked to an array of adverse cardiovascular consequences in HD patients, the first-line approach for the treatment of intradialytic hypertension is likely judicious target weight reduction. Increased UF and careful target weight reduction have been shown to improve intradialytic hypertension [58]. Related, dietary salt intake should be restricted as a means to reduce IDWG. While these interventions will 
not resolve intradialytic hypertension in all patients, $\mathrm{BP}$ improvement in some patients is to be expected. However, volume challenges may exacerbate intradialytic hypertension in some patients as some data suggest overactivation of the RAAS and sympathetic nervous system in response to UF and associated cardiac preload reduction [67].

For patients not responsive to volume challenge, medication regimens should be carefully reviewed. Withholding antihypertensives prior to dialysis is a common practice and should be reconsidered in patients with intradialytic hypertension. Highly dialyzable antihypertensive drugs should be avoided or dosed post dialysis. In addition, ESA dosage should be reduced as much as safely possible and subcutaneous administration considered. Second, pharmaceutical interventions such as adrenergic blockers may be effective among patients with chronic intradialytic hypertension. Beta-blockers with alpha-receptor activity, such as carvedilol, are non-dialyzable and have been shown to reduce intradialytic hypertension, likely via their pleiotropic effects on endothelial cells. In a prospective, 12-week, pilot crossover study of $25 \mathrm{HD}$ patients with intradialytic hypertension, treatment with carvedilol $50 \mathrm{mg}$ twice daily reduced post-HD BP, 44 hour ambulatory BP and frequency of intradialytic hypertension episodes. Modest improvements in endothelial cell dysfunction were also demonstrated [63]. UF-induced activation of the RAAS may also contribute to intradialytic hypertension, suggesting that ACE inhibitors or angiotensin receptor blockers may be effective [68]. As the majority of ACE inhibitors are dialyzable, angiotensin receptor blockers may be better choices for patients with intradialytic hypertension.

Finally, dialysate prescription alterations may reduce intradialytic hypertension. Positive sodium balance is associated with thirst, IDWG and subsequent volume-mediated hypertension as well as endothelial dysfunction and associated endothelin-1-nitric oxide imbalance. HD prescription strategies aimed at reduction of serum sodium and the dialysate-serum sodium gradient may be beneficial. This hypothesis was recently tested in a 3 week, 2 -arm randomized, crossover study in which $16 \mathrm{HD}$ patients with intradialytic hypertension were randomized to low versus high dialysate-serum sodium gradients. Low dialysate sodium concentrations $(5 \mathrm{mEq} / \mathrm{L}$ below serum sodium) were associated with decreased mean BPs [64]. Finally, high dialysate calcium prescriptions should be avoided in patients without hypocalcemia as a means to limit intradialytic hypertension from calcium-enhanced cardiac contractility.

\section{Intradialytic BP Variability}

\section{Epidemiology, Definitions and Outcome Associations}

While both hypotension and hypertension are wellestablished risk factors for adverse outcomes, BP deviation from the expected course, termed BP variability, has recently come to light as a prognostic factor. The majority of BP variability studies in the general and HD populations have considered long-term, visit-to-visit BP variability, measured at clinical visits across days, weeks or months. In the general population, greater long-term BP variability is associated with stroke, heart disease and mortality [69]. Among HD patients, long-term BP variability is measured with pre-HD BPs on a HD treatmentto-treatment basis and is associated with cardiovascular morbidity and mortality $[70,71]$. Recent data suggest that short-term BP variability, considered as intradialytic BP fluctuations, is a cardiovascular risk factor among $\mathrm{HD}$ patients [72]. While some BP fluctuations in response to changing physiologic conditions are to be expected during dialysis, marked deviation from the expected intradialytic BP course is associated with adverse outcomes and is relevant to this review.

Intradialytic BP variability refers to BP fluctuations that are independent of other BP phenomena occurring during dialysis. This important distinction prevents conflation of the prognostic significance of BP fluctuations during HD with that of other intradialytic BP abnormalities. When considering intradialytic BP fluctuations, BP variability must be independent of pre-HD systolic $B P$ and the expected biphasic intradialytic BP decline. BP variability can be defined by several metrics including standard deviation, absolute real variability, residuals derived from linear models and others. Residuals derived from linear mixed models with a spline function have been used to describe intradialytic systolic BP variability as they capture fluctuations from the expected 2-slope intradialytic BP course. Patient and procedural factors associated with variability from this expected course include older age, heart failure, heart disease, diabetes, greater UF volume, more rapid UF rates and larger IDWG [73].

In a study of 6,393 prevalent HD patients using absolute regression residuals from a linear effects model with a 2-slope spline, Flythe et al. [72] demonstrated an association between greater intradialytic systolic BP variability and increased all-cause and cardiovascular mortalities. High BP variability (defined as an absolute systolic $\mathrm{BP}$ residual $>8.7 \mathrm{~mm} \mathrm{Hg}$, the cohort median) was associated with a $32 \%$ higher hazard of death $(\mathrm{p}=0.04)$ com- 
Table 4. Knowledge gaps regarding intradialytic BP abnormalities

Intradialytic hypotension and hypertension

Evidence-based definitions and thresholds for intervention

Objective volume status measures including roles of bioimpedance and blood volume monitoring

Efficacy of UF profiling and sequential UF + dialysis in preventing BP falls and rises

Identification of optimal dialysate-serum sodium gradient differentials

Development of evidence-based prevention protocols

Development of evidence-based treatment protocols

Prospective evaluations of pathophysiologic mechanisms to confirm cross-sectional study findings

Intradialytic BP variability

Evidence-based definition and thresholds for intervention

Clinically accessible measure and assessment tool

Effective mitigation strategies

Confirmation of observational study results in prospective patient cohorts

pared to low BP variability. When BP variability was considered in quartiles, dose-response relationships between $\mathrm{BP}$ variability and all-cause $(\mathrm{p}=0.001)$ and cardiovascular $(\mathrm{p}=0.04)$ mortality was observed. While this study provides strong support for an association between increased intradialytic BP variability and mortality, it is the sole investigation on this topic.

\section{Pathophysiology and Management}

In general, the pathophysiology of BP variability is not well-defined, but there are several plausible mediators. Impaired endothelial function, heightened inflammation, increased vessel wall stress, baroreceptor dysfunction and enhanced sympathetic nervous system activity are all potential contributors to BP variability [74]. Among dialysis patients, HD treatment fluid and osmolar shifts promote random BP fluctuations. Stiff vasculature, reduced cardiac output, autonomic dysfunction and neurohormonal imbalance that are common among HD patients may amplify these fluctuations and engender vulnerability to hemodynamic changes. Thus, BP fluctuations may induce subclinical end-organ hypoperfusion and subject patients to alternating periods of tissue hypoxia and capillary shear stress.

Recommendations regarding management of intradialytic BP variability are non-existent due to 2 key limitations: (1) lack of a clinically accessible chairside measure and (2) absence of studies investigating effective intervention strategies. First, to adequately distinguish intradialytic BP variability from the expected temporal BP course during HD, complex analytical approaches must be employed. The existing BP variability metrics are not easily calculated and are appropriate for research, but not for clinical settings. Thus, clinicians have no way to ob- jectively classify BP variability. Second, clinical outcomes data for intradialytic variability are limited to a single study. This evidence suggests that risk factors for shortterm (intradialytic) and long-term (visit-to-visit) BP variability may differ. Shafi et al. [71] demonstrated that greater UF was associated with lesser long-term (visit-tovisit) $\mathrm{BP}$ variability, but Flythe et al. [73] reported that greater UF was associated with greater short-term (intradialytic) BP variability. These conflicting findings are not surprising given the differences in hemodynamic environments of the intra- and interdialytic periods. Prior to making recommendations about management of intradialytic BP variability, the relative importance of longterm (visit-to-visit) and short-term (intradialytic) BP variability among dialysis patients must be established, and investigations examining mitigation strategies such as changes in fluid removal practice or perhaps antihypertensive agent selection must be conducted. Until then, it is prudent to minimize large BP fluctuations during dialysis by carefully monitoring hemodynamics, volume status and medication effects.

\section{Conclusion}

Existing observational studies provide compelling data supporting associations between intradialytic BP phenomena including hypotension, hypertension and variability and clinical outcomes. Unfortunately, the evidence base for effective management strategies of these dynamic BP changes is weak overall. We lack prospective studies, including randomized trials, confirming optimal diagnostic criteria, evaluating BP thresholds for intervention, assessing the clinical benefit of different interven- 
tion strategies and comparing preventative strategies. Table 4 provides an overview of evidence gaps that provide fertile ground for future research.

Despite these evidence limitations and clinical uncertainties, numerous peridialytic and intradialytic BP measurements confront dialysis unit staff and clinicians during $\mathrm{HD}$ administration. Emerging data suggest that vigilance for hemodynamic fluctuations beyond those associated with overt symptoms is prudent, adding further nuance and complexity to chairside BP interpretation and management. To confront this challenge, providers must draw upon their longitudinal patient relationships, enriched by knowledge about historical BP trends, treatment tolerance, volume status, prescription medications and health status garnered from frequent, attentive patient visits during dialysis. Careful volume assessment through physical examination, interdialytic BP evaluation and HD treatment response, supplemented by data from blood volume monitors and bioimpedance, when avail- able, is paramount. Until prospective studies elucidate the optimal management approaches to intradialytic hypotension, hypertension and variability, individualized prescriptions of antihypertensives, dialysate composition and fluid removal along with close hemodynamic monitoring are the most appropriate therapeutic approaches to limit harm from intradialytic BP fluctuations.

\section{Disclosure Statement}

Dr. J.E. Flythe has received speaking honorarium from Dialysis Clinic, Inc. Dr. M.M. Assimon has no related disclosures.

\section{Funding}

Dr. M.M. Assimon is supported by National Institute of Diabetes and Digestive and Kidney Diseases of the National Institute of Health Grant T32 DK007750.

\section{References}

1 Agarwal R, Peixoto AJ, Santos SF, Zoccali C: Pre- and postdialysis blood pressures are imprecise estimates of interdialytic ambulatory blood pressure. Clin J Am Soc Nephrol 2006; 1:389-398.

2 Alborzi P, Patel N, Agarwal R: Home blood pressures are of greater prognostic value than hemodialysis unit recordings. Clin J Am Soc Nephrol 2007;2:1228-1234.

3 Agarwal R, Bills JE, Hecht TJ, Light RP: Role of home blood pressure monitoring in overcoming therapeutic inertia and improving hypertension control: a systematic review and meta-analysis. Hypertension 2011;57:29-38.

4 Zager PG, Nikolic J, Brown RH, Campbell MA, Hunt WC, Peterson D, Van Stone J, Levey A, Meyer KB, Klag MJ, Johnson HK, Clark E, Sadler JH, Teredesai P: 'U' Curve association of blood pressure and mortality in hemodialysis patients. Medical Directors of Dialysis Clinic, Inc. Kidney Int 1998;54:561569.

5 Park J, Rhee CM, Sim JJ, Kim YL, Ricks J, Streja E, Vashistha T, Tolouian R, Kovesdy CP, Kalantar-Zadeh K: A comparative effectiveness research study of the change in blood pressure during hemodialysis treatment and survival. Kidney Int 2013;84:795-802.

6 Agarwal R, Metiku T, Tegegne GG, Light RP, Bunaye Z, Bekele DM, Kelley K: Diagnosing hypertension by intradialytic blood pressure recordings. Clin J Am Soc Nephrol 2008;3: 1364-1372.

7 Agarwal R, Brim NJ, Mahenthiran J, Andersen MJ, Saha C: Out-of-hemodialysis-unit blood pressure is a superior determinant of left ventricular hypertrophy. Hypertension 2006;47:62-68.

8 Rahman M, Griffin V, Kumar A, Manzoor F, Wright JT Jr, Smith MC: A comparison of standardized versus 'usual' blood pressure measurements in hemodialysis patients. Am J Kidney Dis 2002;39:1226-1230.

9 Perloff D, Grim C, Flack J, Frohlich ED, Hill M, McDonald M, Morgenstern BZ: Human blood pressure determination by sphygmomanometry. Circulation 1993;88(5 pt 1):2460-2470.

10 Agarwal R, Andersen MJ, Bishu K, Saha C: Home blood pressure monitoring improves the diagnosis of hypertension in hemodialysis patients. Kidney Int 2006;69:900-906.

11 Dinesh K, Kunaparaju S, Cape K, Flythe JE, Feldman HI, Brunelli SM: A model of systolic blood pressure during the course of dialysis and clinical factors associated with various blood pressure behaviors. Am J Kidney Dis 2011;58:794-803.

12 Flythe JE, Xue H, Lynch KE, Curhan GC, Brunelli SM: Association of mortality risk with various definitions of intradialytic hypotension. J Am Soc Nephrol 2015;26:724-734.

13 Sands JJ, Usvyat LA, Sullivan T, Segal JH, Zabetakis P, Kotanko P, Maddux FW, Diaz-Buxo JA: Intradialytic hypotension: frequency, sources of variation and correlation with clinical outcome. Hemodial Int 2014;18:415-422.

14 Burton JO, Jefferies HJ, Selby NM, McIntyre CW: Hemodialysis-induced cardiac injury: determinants and associated outcomes. Clin J Am Soc Nephrol 2009;4:914-920.

15 Burton JO, Jefferies HJ, Selby NM, McIntyre CW: Hemodialysis-induced repetitive myo- cardial injury results in global and segmental reduction in systolic cardiac function. Clin J Am Soc Nephrol 2009;4:1925-1931.

16 Chang TI, Paik J, Greene T, Desai M, Bech F, Cheung AK, Chertow GM: Intradialytic hypotension and vascular access thrombosis. J Am Soc Nephrol 2011;22:1526-1533.

17 McIntyre CW, Goldsmith DJ: Ischemic brain injury in hemodialysis patients: which is more dangerous, hypertension or intradialytic hypotension? Kidney Int 2015;87:1109-1115.

18 National Kidney Foundation: KDOQI clinical practice guidelines on hypertension and antihypertensive agents in chronic kidney disease. 2012. http://www.kidney.org/professionals/ kdoqi/guidelines_bp/ (accessed December 6, 2015.

19 Kooman J, Basci A, Pizzarelli F, Canaud B, Haage P, Fouque D, Konner K, Martin-Malo A, Pedrini L, Tattersall J, Tordoir J, Vennegoor M, Wanner C, ter Wee P, Vanholder R: EBPG guideline on haemodynamic instability. Nephrol Dial Transplant 2007;22(suppl 2): ii22-ii44.

20 Dubin R, Owens C, Gasper W, Ganz P, Johansen K: Associations of endothelial dysfunction and arterial stiffness with intradialytic hypotension and hypertension. Hemodial Int 2011;15:350-358.

21 Zhou YL, Liu HL, Duan XF, Yao Y, Sun Y, Liu $\mathrm{Q}$ : Impact of sodium and ultrafiltration profiling on haemodialysis-related hypotension. Nephrol Dial Transplant 2006;21:3231-3237.

22 John AS, Tuerff SD, Kerstein MD: Nonocclusive mesenteric infarction in hemodialysis patients. J Am Coll Surg 2000;190:84-88. 
23 Oliver MJ, Edwards LJ, Churchill DN: Impact of sodium and ultrafiltration profiling on hemodialysis-related symptoms. J Am Soc Nephrol 2001;12:151-156.

24 Chesterton LJ, Selby NM, Burton JO, McIntyre CW: Cool dialysate reduces asymptomatic intradialytic hypotension and increases baroreflex variability. Hemodial Int 2009;13:189-196

25 Meredith DJ, Pugh CW, Sutherland S, Tarassenko L, Birks J: The relationship between symptoms and blood pressure during maintenance hemodialysis. Hemodial Int 2015;19: 543-552.

26 Daugirdas JT: Dialysis hypotension: a hemodynamic analysis. Kidney Int 1991;39:233246.

27 Chesterton LJ, Selby NM, Burton JO, Fialova J, Chan C, McIntyre CW: Categorization of the hemodynamic response to hemodialysis: the importance of baroreflex sensitivity. Hemodial Int 2010;14:18-28

28 McIntyre CW, Harrison LE, Eldehni MT, Jefferies HJ, Szeto CC, John SG, Sigrist MK, Burton JO, Hothi D, Korsheed S, Owen PJ, Lai KB, Li PK: Circulating endotoxemia: a novel factor in systemic inflammation and cardiovascular disease in chronic kidney disease. Clin J Am Soc Nephrol 2011;6:133-141.

29 Shafi T, Jaar BG, Plantinga LC, Fink NE, Sadler JH, Parekh RS, Powe NR, Coresh J: Association of residual urine output with mortality, quality of life, and inflammation in incident hemodialysis patients: the choices for healthy outcomes in caring for end-stage renal disease (CHOICE) study. Am J Kidney Dis 2010;56:348-358.

30 Tislér A, Akócsi K, Borbás B, Fazakas L, Ferenczi S, Görögh S, Kulcsár I, Nagy L, Sámik J, Szegedi J, Tóth E, Wágner G, Kiss I: The effect of frequent or occasional dialysis-associated hypotension on survival of patients on maintenance haemodialysis. Nephrol Dial Transplant 2003;18:2601-2605.

31 Shoji T, Tsubakihara Y, Fujii M, Imai E: Hemodialysis-associated hypotension as an independent risk factor for two-year mortality in hemodialysis patients. Kidney Int 2004;66 1212-1220.

32 Stefánsson BV, Brunelli SM, Cabrera C, Rosenbaum D, Anum E, Ramakrishnan K, Jensen DE, Stålhammar NO: Intradialytic hypotension and risk of cardiovascular disease. Clin J Am Soc Nephrol 2014;9:21242132.

33 Burton JO, Jefferies HJ, Selby NM, McIntyre CW: Hemodialysis-induced cardiac injury: determinants and associated outcomes. Clin J Am Soc Nephrol 2009;4:914-920.

34 Hung SY, Hung YM, Fang HC, Yeh JH, Hung GC, Wu CJ, Chou KJ, Chung HM: Cardiac troponin I and creatine kinase isoenzyme $\mathrm{MB}$ in patients with intradialytic hypotension. Blood Purif 2004;22:338-343.

35 Knoll GA, Grabowski JA, Dervin GF, O'Rourke K: A randomized, controlled trial of albumin versus saline for the treatment of intradialytic hypotension. J Am Soc Nephrol 2004; 15:487-492.

36 Nette RW, Krepel HP, van den Meiracker AH, Weimar W, Zietse R: Specific effect of the infusion of glucose on blood volume during haemodialysis. Nephrol Dial Transplant 2002;17:1275-1280.

37 Flythe JE, Kshirsagar AV, Falk RJ, Brunelli SM: Associations of posthemodialysis weights above and below target weight with all-cause and cardiovascular mortality. Clin J Am Soc Nephrol 2015;10:808-816.

38 Chazot C, Wabel P, Chamney P, Moissl U, Wieskotten S, Wizemann V: Importance of normohydration for the long-term survival of haemodialysis patients. Nephrol Dial Transplant 2012;27:2404-2410.

39 Onofriescu M, Hogas S, Voroneanu L, Apetrii M, Nistor I, Kanbay M, Covic AC: Bioimpedance-guided fluid management in maintenance hemodialysis: a pilot randomized controlled trial. Am J Kidney Dis 2014;64:111118.

40 Santoro A, Mancini E, Basile C, Amoroso L, Di Giulio S, Usberti M, Colasanti G, Verzetti G, Rocco A, Imbasciati E, Panzetta G, Bolzani $\mathrm{R}$, Grandi F, Polacchini M: Blood volume controlled hemodialysis in hypotensionprone patients: a randomized, multicenter controlled trial. Kidney Int 2002;62:10341045 .

41 Song JH, Park GH, Lee SY, Lee SW, Lee SW, Kim MJ: Effect of sodium balance and the combination of ultrafiltration profile during sodium profiling hemodialysis on the maintenance of the quality of dialysis and sodium and fluid balances. J Am Soc Nephrol 2005; 16 : 237-246.

42 de Paula FM, Peixoto AJ, Pinto LV, Dorigo D, Patricio PJ, Santos SF: Clinical consequences of an individualized dialysate sodium prescription in hemodialysis patients. Kidney Int 2004;66:1232-1238.

43 Kalantar-Zadeh K, Regidor DL, Kovesdy CP, Van Wyck D, Bunnapradist S, Horwich TB, Fonarow GC: Fluid retention is associated with cardiovascular mortality in patients undergoing long-term hemodialysis. Circulation 2009;119:671-679.

44 Eldehni MT, Odudu A, McIntyre CW: Randomized clinical trial of dialysate cooling and effects on brain white matter. J Am Soc Nephrol 2015;26:957-965.

45 Selby NM, McIntyre CW: A systematic review of the clinical effects of reducing dialysate fluid temperature. Nephrol Dial Transplant 2006;21:1883-1898.

46 Flythe JE, Mangione TW, Brunelli SM, Curhan GC: Patient-stated preferences regarding volume-related risk mitigation strategies for hemodialysis. Clin J Am Soc Nephrol 2014;9:1418-1425.

47 van der Sande FM, Cheriex EC, van Kuijk WH, Leunissen KM: Effect of dialysate calcium concentrations on intradialytic blood pressure course in cardiac-compromised patients. Am J Kidney Dis 1998;32:125-131.
48 Prakash S, Garg AX, Heidenheim AP, House AA: Midodrine appears to be safe and effective for dialysis-induced hypotension: a systematic review. Nephrol Dial Transplant 2004;19:2553-2558.

49 Lynch KE, Feldman HI, Berlin JA, Flory J, Rowan CG, Brunelli SM: Effects of L-carnitine on dialysis-related hypotension and muscle cramps: a meta-analysis. Am J Kidney Dis 2008;52:962-971.

50 Razeghi E, Dashti-Khavidaki S, Nassiri S, Abolghassemi R, Khalili H, Hashemi Nazari SS, Mansournia MA, Taraz M: A randomized crossover clinical trial of sertraline for intradialytic hypotension. Iran J Kidney Dis 2015; 9:323-330.

51 Imai E, Fujii M, Kohno Y, Kageyama H, Nakahara K, Hori M, Tsubakihara Y: Adenosine A1 receptor antagonist improves intradialytic hypotension. Kidney Int 2006;69:877-883.

52 Inrig JK, Oddone EZ, Hasselblad V, Gillespie B, Patel UD, Reddan D, Toto R, Himmelfarb J, Winchester JF, Stivelman J, Lindsay RM, Szczech LA: Association of intradialytic blood pressure changes with hospitalization and mortality rates in prevalent ESRD patients. Kidney Int 2007;71:454-461.

53 Inrig JK, Patel UD, Toto RD, Szczech LA: Association of blood pressure increases during hemodialysis with 2 -year mortality in incident hemodialysis patients: a secondary analysis of the Dialysis Morbidity and Mortality Wave 2 Study. Am J Kidney Dis 2009;54:881890

54 Inrig JK: Intradialytic hypertension: a lessrecognized cardiovascular complication of hemodialysis. Am J Kidney Dis 2010;55:580589.

55 Van Buren PN, Kim C, Toto RD, Inrig JK: The prevalence of persistent intradialytic hypertension in a hemodialysis population with extended follow-up. Int J Artif Organs 2012;35: 1031-1038.

56 Fellner S: Intradialytic hypertension: II. Semin Dial 1993;6:371-373.

57 Dorhout Mees EJ: Rise in blood pressure during hemodialysis-ultrafiltration: a 'Paradoxical' phenomenon? Int J Artif Organs 1996;19: 569-570.

58 Cirit M, Akçiçek F, Terzioğlu E, Soydaş C, Ok E, Ozbaşli CF, Başçi A, Mees EJ: 'Paradoxical' rise in blood pressure during ultrafiltration in dialysis patients. Nephrol Dial Transplant 1995;10:1417-1420.

59 Agarwal R, Light RP: Intradialytic hypertension is a marker of volume excess. Nephrol Dial Transplant 2010;25:3355-3361.

60 Chou KJ, Lee PT, Chen CL, Chiou CW, Hsu CY, Chung HM, Liu CP, Fang HC: Physiological changes during hemodialysis in patients with intradialysis hypertension. Kidney Int 2006;69:1833-1838.

61 El-Shafey EM, El-Nagar GF, Selim MF, El-Sorogy HA, Sabry AA: Is there a role for endothelin-1 in the hemodynamic changes during hemodialysis? Clin Exp Nephrol 2008;12: 370-375. 
62 Abraham PA, Macres MG: Blood pressure in hemodialysis patients during amelioration of anemia with erythropoietin. J Am Soc Nephrol 1991;2:927-936.

63 Inrig JK, Van Buren P, Kim C, Vongpatanasin W, Povsic TJ, Toto R: Probing the mechanisms of intradialytic hypertension: a pilot study targeting endothelial cell dysfunction. Clin J Am Soc Nephrol 2012;7:1300-1309.

64 Inrig JK, Molina C, D’Silva K, Kim C, Van Buren P, Allen JD, Toto R: Effect of low versus high dialysate sodium concentration on blood pressure and endothelial-derived vasoregulators during hemodialysis: a randomized crossover study. Am J Kidney Dis 2015;65: 464-473.

65 Yang CY, Yang WC, Lin YP: Postdialysis blood pressure rise predicts long-term outcomes in chronic hemodialysis patients: a four-year prospective observational cohort study. BMC Nephrol 2012;13:12.

66 Van Buren PN, Toto R, Inrig JK: Interdialytic ambulatory blood pressure in patients with intradialytic hypertension. Curr Opin Nephrol Hypertens 2012;21:15-23.
67 Izzo JE, Campese VM: Hypertension and renal disease; in Brenner B (ed): Brenner and Rector's the Kidney. Philadelphia, WB Saunders, 2004, pp 2110-2138.

68 Bazzato G, Coli U, Landini S, Lucatello S, Fracasso A, Morachiello P, Righetto F, Scanferla F: Prevention of intra- and postdialytic hypertensive crises by captopril. Contrib Nephrol 1984;41:292-298.

69 Muntner P, Whittle J, Lynch AI, Colantonio LD, Simpson LM, Einhorn PT, Levitan EB, Whelton PK, Cushman WC, Louis GT, Davis BR, Oparil S: Visit-to-visit variability of blood pressure and coronary heart disease, stroke, heart failure, and mortality: a cohort study. Ann Intern Med 2015;163:329-338.

70 Chang TI, Flythe JE, Brunelli SM, Muntner P, Greene T, Cheung AK, Chertow GM: Visitto-visit systolic blood pressure variability and outcomes in hemodialysis. J Hum Hypertens $2014 ; 28: 18-24$
71 Shafi T, Sozio SM, Bandeen-Roche KJ, Ephraim PL, Luly JR, St Peter WL, McDermott A, Scialla JJ, Crews DC, Tangri N, Miskulin DC, Michels WM, Jaar BG, Herzog CA, Zager PG, Meyer KB, Wu AW, Boulware LE; DEcIDE Network Patient Outcomes in End Stage Renal Disease Study Investigators: Predialysis systolic BP variability and outcomes in hemodialysis patients. J Am Soc Nephrol 2014;25:799-809.

72 Flythe JE, Inrig JK, Shafi T, Chang TI, Cape K, Dinesh K, Kunaparaju S, Brunelli SM: Association of intradialytic blood pressure variability with increased all-cause and cardiovascular mortality in patients treated with longterm hemodialysis. Am J Kidney Dis 2013;61: 966-974.

73 Flythe JE, Kunaparaju S, Dinesh K, Cape K, Feldman HI, Brunelli SM: Factors associated with intradialytic systolic blood pressure variability. Am J Kidney Dis 2012;59:409-418.

74 Rothwell PM: Limitations of the usual bloodpressure hypothesis and importance of variability, instability, and episodic hypertension. Lancet 2010;375:938-948. 